\title{
The Association Between Self-Reported Symptoms of Recent Airway Infection and CRP Values in a General Population
}

\author{
Hasse Melbye, ${ }^{1,5}$ Kristine Amundsen, ${ }^{1}$ Jan Brox, ${ }^{2,3}$ and Anne-Elise Eggen ${ }^{4}$
}

\begin{abstract}
C-reactive protein (CRP) is a much used biomarker for respiratory tract infection; however, the influence of airway infection on the CRP level in the general population has not been well described. The study aimed to evaluate the impact of recent symptoms of airway infection on the CRP level and how the predictive power of other known CRP predictors is influenced by taking respiratory symptoms into account. A total of 6,325 participants, aged 38-87 years, in the Tromsø Study, a repeated population-based survey, were examined with questionnaires, measurements of height and weight, spirometry, and high-sensitivity CRP analyses. The mean CRP value was 2.8$6 \mathrm{mg} / \mathrm{L}$, and the geometric mean was $1.51 \mathrm{mg} / \mathrm{L}$. Geometric means above $2.0 \mathrm{mg} / \mathrm{L}$ were found in the subgroups with the following characteristics: self-reported COPD, diabetes, recent symptoms of airway infection, forced expiratory volume in $1 \mathrm{~s}$ (FEV1) $<80 \%$ predicted, body mass index (BMI) $\geq 30$, and subjects treated with inhaled or oral corticosteroids. Among the subjects who reported recent airway infection, $10.5 \%$ had a CRP value of $\geq 10 \mathrm{mg} / \mathrm{L}$, compared to $3.3 \%$ among the remaining participants. By multivariate analysis, BMI was the strongest independent predictor of the CRP level, followed by recent airway infection, FEV1\% predicted, age, and current smoking. The study clearly demonstrates that a report of recent symptoms of airway infection strongly predicts the CRP level in the population. Such symptoms were shared rather equally between subgroups with increased CRP level, and the risk of being an important confounder in epidemiological studies is probably low. In the clinical setting, care should be taken when using the CRP level as a guide for medical prevention of chronic diseases.
\end{abstract}

KEY WORDS: C-reactive protein; general population; systemic inflammation; respiratory tract infection.

\section{INTRODUCTION}

C-reactive protein (CRP) has, since its discovery, been associated with airway infections. The name of the acute phase protein originates from its link to pneumococcal infection [1]. CRP values above $100 \mathrm{mg} / \mathrm{L}$ are frequently

\footnotetext{
${ }^{1}$ General Practice Research Unit, Department of Community Medicine, Faculty of Health Science, University of Tromsø, 9037 Tromsø, Norway

${ }^{2}$ Department of Medical Biology, Faculty of Health Science, University of Tromsø, Tromsø, Norway

${ }^{3}$ Department of Laboratory Medicine, University Hospital of North Norway, Tromsø, Norway

${ }^{4}$ Department of Community Medicine, Faculty of Health Science, University of Tromsø, Tromsø, Norway

${ }^{5}$ To whom correspondence should be addressed at General Practice Research Unit, Department of Community Medicine, Faculty of Health Science, University of Tromsø, 9037 Tromsø, Norway. E-mail: hasse.melbye@uit.no
}

found in patients hospitalized with pneumonia [2, 3], and the biomarker is used in the monitoring of pneumonia in intensive care units [4]. The CRP test has also been found to be useful in diagnosing pneumonia in primary care $[5$, $6]$, although elevated values may also be found in viral respiratory infections $[7,8]$, with peak levels after 3-4 days of illness [8]. High CRP levels are also found in other acute infections, rheumatic and inflammatory diseases, acute cardiovascular events, and cancer [9-11].

When high-sensitivity methodology has been applied in the study of CRP levels in the general population, increased levels have been associated with increased risk of cancer [12] and coronary heart disease, including myocardial infarction [10]. Statin use has been found to lower both the CRP level and the incidence of myocardial infarction, and CRP levels down to $3 \mathrm{mg} / \mathrm{L}$, and even $2 \mathrm{mg} / \mathrm{L}$, have been suggested as a support for prescribing statins [13]. Corticosteroids are also anti-inflammatory drugs that lower 
the CRP level [14, 15]. Estrogens have an opposite effect, however probably by altering the metabolism of CRP [16].

Raised CRP level by increasing age has been found in studies on the CRP level in a general population [17, 18]. This may be related to the increased morbidity of cancer and cardiovascular diseases with increasing age, but may also be partly explained by the impact of agerelated factors like pack-years of smoking [19] and the prevalence of bronchial airflow limitation [20]. A very strong predictor, not related to age in the adult population, is obesity [21] or the body mass index (BMI) [20].

The temporary increase in the CRP level due to respiratory tract infection is a potential confounder both when clinicians consider statin treatment based on the CRP value and when epidemiologists study the effect of chronic diseases and medication on the CRP level. However, the explanatory variable of airway infections has not been taken into account in the major populationbased studies on CRP [17, 18, 22-24], except in NHANES [25]. The aim of our study was to describe the influence of recent symptoms of airway infection on the CRP value, which till now has not been well described. We also wanted to shed light on how the evaluation of other CRP predictors can be influenced by taking such symptoms into account.

\section{METHODS}

\section{Subjects}

The subjects studied were participants in the Tromsø Study, an epidemiological, prospective study of health problems, symptoms, and chronic diseases with repeated surveys since 1974 [26]. Tromsø is a city in the northern part of Norway with 69,000 inhabitants. The participants attended the sixth survey, conducted between October 2007 and December 2008. The Department of Community Medicine, University of Tromsø, has the scientific leadership and administration of the Tromsø Study.

Subjects invited to participate in Troms $\varnothing 6$ included all residents aged $40-42$ or $60-87$, a $10 \%$ random sample of individuals aged 30-39, a $40 \%$ random sample of individuals aged 43-59, and subjects who had attended the second visit of Tromsø 4, if not already included in the three groups above. The Population Registry of Norway, with a unique national identity number given to all citizens, was the source for the invitations.
The attendance rate was $65.7 \%$, giving 12,984 individuals attending the first visit, which included a questionnaire on topics such as family and social background, lifestyle, self-rated health, previous medical record, and use of health services, and clinical examinations and anthropometric measurements. About two thirds of the participants who attended the first visit were invited to a second visit with more extended medical examination if they fulfilled one of the following criteria:

- All subjects aged 50-62 or aged 75-84

- A 20\% random sample of men and women aged 63-74

- Subjects, if not already included in the two groups above, who had attended the second visit of Tromsø 4.

A total of 7,958 subjects who met at the first visit were invited to the second visit, in which our study was a part, and 7,307 attended (91.8\%).

\section{Examinations}

Before attending the first visit, the participants had to fill in a questionnaire on health issues including current and previous illness, smoking habit, and use of medication. Participants who reported "asthma" or "chronic bronchitis/emphysema/COPD" were classified as "asthma or COPD." Those reporting angina pectoris, myocardial infarction, cerebral stroke, or atrial fibrillation were classified as "self-reported cardiovascular disease." The brand names of medicine used regularly during the 4 weeks preceding the study were reported and registered on the fifth level of the Anatomical Therapeutic Chemical (ATC) system, version 2007. Participants reporting a proprietary name of a statin (ATC group C10AA) were classified as statin users in the analysis. Use of inhaled and systemic corticosteroids was defined from self-report of brand names belonging to ATC groups R03BA and R03AK, and $\mathrm{H} 02 \mathrm{AB}$, respectively. Participants reporting use of blood pressure-lowering drugs were classified as users regardless of reported brand names. Use of systemic estrogens, (hormone therapy for menopausal symptoms, HT) was reported by women. Height and weight were measured during the first visit.

At the spirometry station during the second visit, a questionnaire concerning recent symptoms of possible RTI was filled in including:

- Have you had any symptoms of common cold, bronchitis, or other airway infection during the last 7 days? 
- If so, how many days have passed since the symptoms started?

- If so, do you have such symptoms today?

This questionnaire was computerized, and each question had to be answered before moving to the next. Immediately after, spirometry was performed by trained technical staff with the use of a "Sensor Medics Vmax Encore 20" spirometer, following ATS/ERS criteria [27] Norwegian reference values were used [28].

On the same day, blood was drawn for CRP analysis. Sera were stored at $-20^{\circ} \mathrm{C}$ until tested. CRP was measured by high-sensitivity (ultrasensitive) CRP method (particle-enhanced immunoturbidimetric assay) in MODULAR P autoanalyzer (Roche/Hitachi) with reagents from Roche Diagnostics $\mathrm{GmbH}$, Mannheim, Germany. The analytical sensitivity (lower detection limit) of this assay is $0.03 \mathrm{mg} / \mathrm{L}$, and the measuring range is $0.1-20 \mathrm{mg} / \mathrm{L}$. The analytical coefficient of variation $(\mathrm{CV})$ is $3.6 \%$. The samples with CRP more than $5 \mathrm{mg} / \mathrm{L}$ were analyzed by immunoturbidimetric method with analyzer and reagents from the same manufacturer.
The analytical sensitivity (lower detection limit) of the assay is $3 \mathrm{mg} / \mathrm{L}$, and the analytical CV is $4.0 \%$. Participants with missing CRP values and those who did not answer the questionnaire on symptoms of recent airway infection were excluded from the statistical analysis.

\section{Statistical Analyses}

The frequency of reporting symptoms indicating recent airway infection and the CRP value were analyzed according to gender, age, and known predictors of the CRP level: smoking habit, self-reported cardiovascular and chronic lung diseases, spirometry results, BMI, and the use of statins, corticosteroids, and estrogens. Differences between groups were analyzed using Mann-Whitney's, Jonckhere-Terpstra, and Chi-square tests. Because CRP values were skewed, geometric means were calculated. The explanatory variables and self-reported medication were entered for multivariable linear regression analysis with log-CRP as the outcome variable. The SPSS 16.0 for Windows (SPSS Inc., Chicago, IL, USA) was used in the statistical analyses.

Table 1. Characteristics of the Participants by Gender of The Tromsø Study: Tromsø 6

\begin{tabular}{|c|c|c|c|c|c|c|}
\hline & \multirow[b]{2}{*}{ All, $n=6,325$} & \multicolumn{2}{|c|}{ Women, $n=3,614$} & \multicolumn{2}{|c|}{ Men, $n=2,711$} & \multirow[b]{2}{*}{$p$ value of gender difference } \\
\hline & & $n$ & $\%$ & $n$ & $\%$ & \\
\hline \multicolumn{7}{|l|}{$\overline{\text { Age }}$} \\
\hline$<65$ years & 3,670 & 2,082 & 57.6 & 1,588 & 58.6 & NS \\
\hline$\geq 65$ years & 2,655 & 1,532 & 42.4 & 1,123 & 41.4 & \\
\hline \multicolumn{7}{|l|}{ Smoking (data missing in 88 ) } \\
\hline Current & 1,147 & 700 & 19.7 & 447 & 16.7 & 0.001 \\
\hline Previous & 2,910 & 1,446 & 40.7 & 1,464 & 54.6 & $<0.001$ \\
\hline Never & 2,180 & 1,408 & 39.6 & 772 & 28.8 & $<0.001$ \\
\hline \multicolumn{7}{|l|}{ Self-reported disease } \\
\hline Asthma & 625 & 408 & 11.6 & 217 & 8.2 & $<0.001$ \\
\hline Chronic bronchitis/emphysema/COPD & 327 & 199 & 5.7 & 128 & 4.9 & NS \\
\hline Cardiovascular disease & 1,129 & 485 & 13.4 & 644 & 23.8 & $<0.001$ \\
\hline Diabetes & 353 & 180 & 5.1 & 173 & 6.5 & 0.01 \\
\hline Symptoms of airway infection last 7 days & 783 & 438 & 12.1 & 345 & 12.7 & NS \\
\hline \multicolumn{7}{|l|}{ Lung function (data missing in 110) } \\
\hline FEV $1<80 \%$ predicted & 1,328 & 697 & 19.3 & 670 & 24.7 & $<0.001$ \\
\hline FEV $1 \geq 80 \%$ predicted & 4,887 & 2,908 & 80.7 & 2,038 & 75.3 & \\
\hline \multicolumn{7}{|l|}{ BMI (data missing in 7 ) } \\
\hline $\mathrm{BMI}<30$ & 4,998 & 748 & 20.7 & 572 & 21.2 & NS \\
\hline $\mathrm{BMI}>30$ & 1,320 & 2,862 & 79.3 & 2,136 & 78.9 & \\
\hline \multicolumn{7}{|l|}{ Self-reported medication } \\
\hline Inhaled corticosteroids & 353 & 240 & 6.6 & 113 & 4.2 & $<0.001$ \\
\hline Oral corticosteroids & 92 & 68 & 1.9 & 24 & 0.9 & 0.001 \\
\hline Antihypertensives & 1,797 & 1,042 & 28.8 & 755 & 27.8 & NS \\
\hline Statins & 1,083 & 551 & 15.2 & 532 & 19.6 & $<0.001$ \\
\hline HT (estrogens) only women & 317 & 317 & 8.8 & & & \\
\hline
\end{tabular}

$N S$ not significant 
A $p$ value $<0.05$ was considered significant. The Tromsø Study complies with the Declaration of Helsinki, and each subject gave written informed consent prior to participation. The Regional Committee of Medical and Health Research Ethics approved the study.

\section{RESULTS}

A total of 6,325 subjects had their CRP measured and also answered the questions on recent airway infection, and were thus included in the study. The mean age was 63.6 years (range, 38-87 years), and $57.1 \%$ were women. Other characteristics and differences between the genders are shown in Table 1 . Symptoms of recent airway infection were reported in
$12.4 \%$, and with significantly increased frequency in current smokers, patients reporting asthma, and those with forced expiratory volume in $1 \mathrm{~s}$ (FEV1) $<80 \%$ predicted (Table 2).

\section{CRP}

CRP values ranged from 0.12 to $175 \mathrm{mg} / \mathrm{L}$, the mean value was $2.86 \mathrm{mg} / \mathrm{L}$, and the median value was $1.38 \mathrm{mg} / \mathrm{L}$, whereas the geometric mean was $1.51 \mathrm{mg} / \mathrm{L}$. No significant difference in geometric mean was observed between men and women (Table 3). Geometric means above $2.0 \mathrm{mg} / \mathrm{L}$ were found in the following subgroups: subjects with self-reported COPD, diabetes, or recent symptoms of airway infection, subjects with FEV1 $<80 \%$ predicted, subjects with $\mathrm{BMI} \geq 30$, and in

Table 2. The Frequency of Reporting Symptoms of Airway Infection 7 Days Before the Examination by Characteristics of the 6,325 Participants

\begin{tabular}{|c|c|c|c|}
\hline & \multicolumn{2}{|c|}{ Symptoms of airway infection for the last 7 days } & \multirow[b]{2}{*}{$p$ value } \\
\hline & $n$ & $\%$ & \\
\hline$\overline{\text { All }}$ & 783 & 12.4 & \\
\hline \multicolumn{4}{|l|}{ Gender } \\
\hline Male & 345 & 12.7 & \multirow[t]{2}{*}{ NS } \\
\hline Female & 438 & 12.1 & \\
\hline \multicolumn{4}{|l|}{ Age } \\
\hline$<65$ years & 486 & 13.2 & \multirow[t]{2}{*}{0.008} \\
\hline$\geq 65$ years & 297 & 11.2 & \\
\hline \multicolumn{4}{|l|}{ Smoking (data missing in 88 ) } \\
\hline Current $(p<0.001)$ & 211 & 18.4 & \multirow[t]{3}{*}{$<0.001$} \\
\hline Previous & 325 & 11.2 & \\
\hline Never & 238 & 10.9 & \\
\hline \multicolumn{4}{|l|}{ Self-reported disease } \\
\hline Asthma & 93 & 14.9 & \multirow[t]{4}{*}{0.02} \\
\hline Chronic bronchitis/emphysema/COPD & 46 & 14.1 & \\
\hline Cardiovascular disease & 130 & 11.5 & \\
\hline Diabetes & 49 & 13.9 & \\
\hline \multicolumn{4}{|l|}{ Lung function (data missing in 110 ) } \\
\hline FEV1 $<80 \%$ predicted & 215 & 16.2 & \multirow[t]{2}{*}{0.008} \\
\hline FEV1 $\geq 80 \%$ predicted & 551 & 11.3 & \\
\hline \multicolumn{4}{|l|}{ BMI (data missing in 7 ) } \\
\hline $\mathrm{BMI}<30$ & 625 & 12.5 & \multirow[t]{2}{*}{ NS } \\
\hline $\mathrm{BMI}>30$ & 158 & 12.0 & \\
\hline \multicolumn{4}{|l|}{ Self-reported medication } \\
\hline Inhaled corticosteroids & 55 & 15.6 & NS \\
\hline Oral corticosteroids & 13 & 14.1 & NS \\
\hline Antihypertensives & 228 & 12.7 & NS \\
\hline Statins & 134 & 12.4 & NS \\
\hline HT (estrogens) & 34 & 10.7 & NS \\
\hline
\end{tabular}

The Tromsø Study: Tromsø 6. The $p$ values show the statistical significance of the difference between the displayed subgroups and between those with and without the displayed characteristics

NS not significant

${ }^{a}$ Current smokers compared with all the others 
Table 3. CRP Values by Characteristics of the 6,325 Participants

\begin{tabular}{|c|c|c|c|c|}
\hline & \multicolumn{4}{|c|}{ CRP } \\
\hline & $n$ & Mean & Geometric mean & $p$ value \\
\hline All & 6,325 & 2.9 & 1.5 & \\
\hline \multicolumn{5}{|l|}{ Gender } \\
\hline Male & 2,711 & 3.1 & 1.6 & \multirow[t]{2}{*}{ NS } \\
\hline Female & 3,614 & 2.7 & 1.5 & \\
\hline \multicolumn{5}{|l|}{ Age } \\
\hline$<65$ years & 3,670 & 1.6 & 1.4 & \multirow[t]{2}{*}{0.001} \\
\hline$\geq 65$ years & 2,655 & 3.3 & 1.7 & \\
\hline \multicolumn{5}{|l|}{ Smoking (data missing in 88 ) } \\
\hline Current & 1,147 & 3.5 & 1.8 & \multirow[t]{3}{*}{$<0.001^{\mathrm{a}}$} \\
\hline Previous & 2,910 & 2.8 & 1.5 & \\
\hline Never & 2,180 & 2.6 & 1.4 & \\
\hline \multicolumn{5}{|l|}{ Self-reported disease } \\
\hline Asthma & 625 & 4.0 & 1.9 & $<0.001$ \\
\hline Chronic bronchitis/emphysema/COPD & 327 & 5.0 & 2.3 & $<0.001$ \\
\hline Cardiovascular disease & 1,129 & 2.9 & 1.6 & 0.003 \\
\hline Diabetes & 353 & 3.7 & 2.1 & $<0.001$ \\
\hline \multicolumn{5}{|l|}{ Symptoms of airway infection last week } \\
\hline Yes & 783 & 5.1 & 2.3 & \multirow[t]{2}{*}{$<0.001$} \\
\hline No & 5,542 & 2.5 & 1.4 & \\
\hline \multicolumn{5}{|l|}{ Lung function (data missing in 110) } \\
\hline FEV1 $<80 \%$ predicted & 1,328 & 4.0 & 2.1 & \multirow[t]{2}{*}{$<0.001$} \\
\hline FEV $1 \geq 80 \%$ predicted & 4,887 & 2.5 & 1.4 & \\
\hline \multicolumn{5}{|l|}{ BMI (data missing in 7) } \\
\hline $\mathrm{BMI}<30$ & 4,998 & 2.5 & 1.3 & \multirow[t]{2}{*}{$<0.001$} \\
\hline $\mathrm{BMI}>30$ & 1,320 & 4.0 & 2.4 & \\
\hline \multicolumn{5}{|l|}{ Self-reported medication } \\
\hline Inhaled corticosteroids & 353 & 5.1 & 2.3 & $<0.001$ \\
\hline Oral corticosteroids & 92 & 5.1 & 2.5 & $<0.001$ \\
\hline Antihypertensives & 1,797 & 3.2 & 1.8 & $<0.001$ \\
\hline Statins & 1,083 & 2.7 & 1.5 & NS \\
\hline HT (estrogens) & 317 & 2.9 & 1.7 & 0.001 \\
\hline
\end{tabular}

The Tromsø Study: Tromsø 6. The $p$ values show the statistical significance of the difference between the displayed subgroups and between those with and without the displayed characteristics

$N S$ not significant

${ }^{a}$ Current smokers compared with all the others

patients treated with inhaled or oral corticosteroids

(Table 3).

\section{CRP and Symptoms of Airway Infection}

Among the subjects who reported recent airway infection, $10.5 \%$ had a CRP value $\geq 10 \mathrm{mg} / \mathrm{L}$, compared to $3.3 \%$ among the remaining subjects. A CRP value $<3 \mathrm{mg} / \mathrm{L}$ was still found in more than $50 \%$ (Fig. 1). The frequency of having a CRP $\geq 10 \mathrm{mg} / \mathrm{L}$ dropped significantly with duration of symptoms (Table 4) from $15 \%$, when the illness had lasted a week or less to $3.8 \%$ when the illness had lasted more than 3 weeks, $p=0.001$ (Chi-square trend). Similar durations of symptoms were found in men and women.

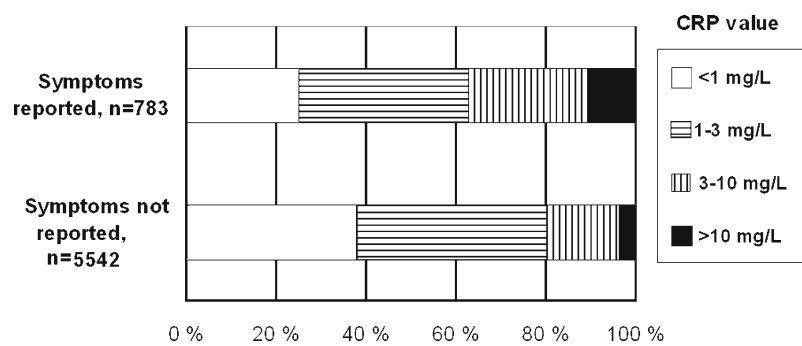

Fig. 1. Distribution of CRP values according to reported/unreported symptoms of airway infection in last week in 6,325 adults. The Tromsø Study: Tromsø 6. 
Table 4. CRP Values in Subjects Reporting Symptoms of Airway Infection in the Last 7 Days, on the Examination Day ( $n=770)$, and by the Duration of Symptoms $(n=778)$

\begin{tabular}{|c|c|c|c|c|}
\hline & \multicolumn{4}{|c|}{ CRP } \\
\hline & $n$ & Mean & Geometric mean & $p$ value \\
\hline \multicolumn{5}{|c|}{ Do you have symptoms of airway infection on the examination day? } \\
\hline Yes & 260 & 6.0 & 2.8 & 0.002 \\
\hline No & 510 & 4.7 & 2.1 & \\
\hline \multicolumn{5}{|c|}{ Duration of the symptoms } \\
\hline$\leq 7$ days & 333 & 6.6 & 2.8 & $<0.001^{\mathrm{a}}$ \\
\hline $8-14$ days & 250 & 4.1 & 2.1 & \\
\hline 15-21 days & 89 & 5.0 & 2.1 & \\
\hline$\geq 22$ days & 106 & 2.9 & 1.8 & \\
\hline
\end{tabular}

\section{Multivariable Analysis}

By multivariable analysis, BMI was the strongest independent predictor of the CRP level, followed by recent airway infection, FEV1\% predicted, age, and current smoking (Table 5). BMI was a particularly strong predictor among women, whereas symptom of airway infection was a stronger predictor among men than among women (Table 5). Multivariate analyses excluding information on symptoms of airway infection gave similar results when analyzed in all participants; the greatest change in standardized beta was observed for current smoking, from 0.10 to 0.12 .

\section{DISCUSSION}

We have confirmed the great importance of airway infection for the CRP level in the general population. As many as $12.4 \%$ of the subjects reported symptoms of airway infection the week before the examination, but

Table 5. Independent Predictors of Log CRP (Milligrams Per Liter) Determined by Linear Multivariate Regression, in 3,466 Women $\left(r^{2}\right.$ of the Model=0.24), 2,626 Men $\left(r^{2}=0.17\right)$, and in both Genders $\left(n=6,093, r^{2}=0.20\right)$ (The Tromsø Study: Tromsø 6)

\begin{tabular}{|c|c|c|c|c|c|c|}
\hline & \multicolumn{2}{|c|}{ Women } & \multicolumn{2}{|c|}{ Men } & \multicolumn{2}{|c|}{ Both genders } \\
\hline & Standardized beta & $p$ value & Standardized beta & $p$ value & Standardized beta & $p$ value \\
\hline \multicolumn{7}{|l|}{ Subject characteristics } \\
\hline Male gender & & & & & 0.00 & NS \\
\hline Age & 0.12 & $<0.001$ & 0.12 & $<0.001$ & 0.13 & $<0.001$ \\
\hline Current smoking & 0.10 & $<0.001$ & 0.13 & $<0.001$ & 0.11 & $<0.001$ \\
\hline Previous smoking & 0.03 & NS & 0.02 & NS & 0.02 & NS \\
\hline \multicolumn{7}{|l|}{ Self-reported disease } \\
\hline Asthma or COPD & 0.02 & NS & 0.02 & NS & 0.03 & NS \\
\hline Cardiovascular disease & -0.02 & NS & -0.02 & NS & -0.02 & NS \\
\hline Diabetes & 0.02 & NS & 0.03 & NS & 0.02 & 0.04 \\
\hline Recent airway infection & 0.12 & $<0.001$ & 0.20 & $<0.001$ & 0.16 & $<0.001$ \\
\hline \multicolumn{7}{|l|}{ Findings } \\
\hline FEV1\% predicted & -0.12 & $<0.001$ & -0.14 & $<0.001$ & -0.13 & $<0.001$ \\
\hline BMI & 0.41 & $<0.001$ & 0.23 & $<0.001$ & 0.34 & $<0.001$ \\
\hline \multicolumn{7}{|l|}{ Self-reported medication } \\
\hline Inhaled corticosteroids & 0.03 & NS & 0.02 & NS & 0.03 & NS \\
\hline Oral corticosteroids & 0.05 & 0.001 & 0.01 & NS & 0.04 & 0.002 \\
\hline Antihypertensives & 0 & NS & 0.4 & 0.03 & 0.02 & NS \\
\hline Statins & -0.06 & $<0.001$ & -0.08 & $<0.001$ & -0.07 & $<0.001$ \\
\hline HT (estrogens) & 0.06 & $<0.001$ & & & 0.05 & $<0.001$ \\
\hline
\end{tabular}

NS not significant 
the majority of these had CRP values below $3 \mathrm{mg} / \mathrm{L}$, probably indicating that very mild infection or just irritation of the airways is common. The highest CRP values were found, as could be expected [8], when the symptoms had lasted less than a week. The respiratory symptoms were rather equally distributed by subgroups, although reported significantly more frequent in current smokers and subjects with reduced lung function. This explains why removing "recent airway infection" from the multivariable analyses only moderately changed how the CRP level was associated with the other known predictors.

The results confirm the major findings in a study based on data from the fifth Tromsø study (Tromsø 5) [20]. Also in this earlier study, BMI, FEV1\% predicted, and current smoking were strong predictors of the CRP value. However, low quality of the "recent airway infection" variable was a problem in that study. Many of the participants had answered the airway infection question many days, and sometimes weeks, before blood was drawn for the CRP test. The correct timing of questions and blood sampling in the current study made the airway infection question a much stronger predictor. In the previous study, only subjects aged 60 years or more were included. The wider range of ages in this study can probably explain why age now had become a stronger predictor in the multivariable analysis.

We did not find any significant association between self-reported cardiovascular disease and the CRP value. This is probably related to the widespread use of statins, which was used in $49.9 \%$ of the patients in this subgroup. This explanation implies, however, that the prescribing of statins has probably been appropriately directed toward persons at high risk of new cardiovascular events, who could be expected to have raised CRP. Diabetes was, on the other hand, an independent predictor of elevated CRP in the multivariable analysis. Statin use was reported by $40.4 \%$ of the subjects reporting diabetes, and a weaker association with the CRP level would probably have been the case if more subjects in this subgroup had been treated with statins. Our analyses confirmed that the association between BMI and CRP is stronger among women than among men, as found by Khera and co-workers [21].

The data on airway infection are based on a questionnaire and not on biological findings, and do not truly reflect the presence of airway infections. We are not able to explain why the association between the CRP value and reported symptoms of airway infection was stronger among men than among women. Could it reflect a more adequate apprehension of symptoms from the airways in men compared to women? The anyhow high predictive power of the question, "Have you had any symptoms of common cold, bronchitis, or other airway infection during the last 7 days?" in the multivariable analysis may indicate that it was well formulated and can be used in future studies. The almost "normal" CRP level when the symptoms had lasted 3 weeks or more may suggest that adding a question on duration of illness may be useful.

To conclude, we have found that recent symptoms of airway infection are a strong predictor of the CRP level in the population. Since such symptoms were rather equally distributed among the various subgroups with increased CRP level in our study, the risk of being an important confounder in epidemiological studies seems to be low. In the clinical setting, however, care should be taken when using the CRP level as support for medical treatment, with, for instance, statins. A persistent raised level, determined by measurements over time, should at least have been documented.

\section{ACKNOWLEDGEMENTS}

This study is a part of the Tromsø Study financed by the Department of Community Medicine, University of Tromsø. KA received a grant from General Practice Research Fund, The Norwegian Medical Association.

Open Access. This article is distributed under the terms of the Creative Commons Attribution Noncommercial License which permits any noncommercial use, distribution, and reproduction in any medium, provided the original author(s) and source are credited.

\section{REFERENCES}

1. Black, S., I. Kushner, and D. Samols. 2004. C-reactive protein. Journal of Biological Chemistry 279(47): 48487-48490.

2. Hansson, L.O., J.U. Hedlund, and A.B. Ortqvist. 1997. Sequential changes of inflammatory and nutritional markers in patients with community-acquired pneumonia. Scandinavian Journal of Clinical and Laboratory Investigation 57(2): 111-118.

3. Smith, R.P., B.J. Lipworth, I.A. Cree, E.M. Spiers, and J.H. Winter. 1995. C-reactive protein. A clinical marker in community-acquired pneumonia. Chest 108(5): 1288-1291.

4. Povoa, P., L. Coelho, E. Almeida, A. Fernandes, R. Mealha, P. Moreira, et al. 2005. C-reactive protein as a marker of ventilator- 
associated pneumonia resolution: a pilot study. European Respiratory Journal 25(5): 804-812.

5. Melbye, H., B. Straume, and J. Brox. 1992. Laboratory tests for pneumonia in general practice: the diagnostic values depend on the duration of illness. Scandinavian Journal of Primary Health Care 10(3): 234-240.

6. Hopstaken, R.M., J.W. Muris, J.A. Knottnerus, A.D. Kester, P.E. Rinkens, and G.J. Dinant. 2003. Contributions of symptoms, signs, erythrocyte sedimentation rate, and $\mathrm{C}$-reactive protein to a diagnosis of pneumonia in acute lower respiratory tract infection. British Journal of General Practice 53(490): 358-364.

7. Ruuskanen, O., A. Putto, H. Sarkkinen, O. Meurman, and K. Irjala. 1985. C-reactive protein in respiratory virus infections. Journal of Pediatrics 107(1): 97-100.

8. Melbye, H., D. Hvidsten, A. Holm, S.A. Nordbo, and J. Brox. 2004. The course of C-reactive protein response in untreated upper respiratory tract infection. British Journal of General Practice 54 (506): 653-658.

9. Pepys, M.B., and G.M. Hirschfield. 2003. C-reactive protein: a critical update. The Journal of Clinical Investigation 111(12): $1805-1812$.

10. Casas, J.P., T. Shah, A.D. Hingorani, J. Danesh, and M.B. Pepys. 2008. C-reactive protein and coronary heart disease: a critical review. Journal of Internal Medicine 264(4): 295-314.

11. Lee, J.S., O.Y. Kwon, H.S. Choi, H.P. Hong, and Y.G. Ko. 2011. Serum C-reactive protein level is a predictive factor for 14-day mortality of patients with advanced cancer who present to the emergency department with acute symptoms. Academic Emergency Medicine 18(4): 440-442.

12. Marsik, C., L. Kazemi-Shirazi, T. Schickbauer, S. Winkler, C. Joukhadar, O.F. Wagner, et al. 2008. C-reactive protein and allcause mortality in a large hospital-based cohort. Clinical Chemistry 54(2): 343-349.

13. Ridker, P.M., J. MacFadyen, P. Libby, and R.J. Glynn. 2010. Relation of baseline high-sensitivity C-reactive protein level to cardiovascular outcomes with rosuvastatin in the Justification for Use of statins in Prevention: an Intervention Trial Evaluating Rosuvastatin (JUPITER). The American Journal of Cardiology 106(2): 204-209.

14. Pinto-Plata, V.M., H. Mullerova, J.F. Toso, M. Feudjo-Tepie, J.B. Soriano, R.S. Vessey, et al. 2006. C-reactive protein in patients with COPD, control smokers and non-smokers. Thorax 61(1): 23-28.

15. Sin, D.D., P. Lacy, E. York, and S.F. Man. 2004. Effects of fluticasone on systemic markers of inflammation in chronic obstructive pulmonary disease. American Journal of Respiratory and Critical Care Medicine 170(7): 760-765.

16. Eilertsen, A.L., E. Hoibraaten, I. Os, T.O. Andersen, L. Sandvik, and P.M. Sandset. 2005. The effects of oral and transdermal hormone replacement therapy on C-reactive protein levels and other inflammatory markers in women with high risk of thrombosis. Maturitas 52(2): 111-118.
17. Imhof, A., M. Frohlich, H. Loewel, N. Helbecque, M. Woodward, P. Amouyel, et al. 2003. Distributions of C-reactive protein measured by high-sensitivity assays in apparently healthy men and women from different populations in Europe. Clinical Chemistry 49(4): 669-672.

18. Hutchinson, W.L., W. Koenig, M. Frohlich, M. Sund, G.D. Lowe, and M.B. Pepys. 2000. Immunoradiometric assay of circulating Creactive protein: age-related values in the adult general population. Clinical Chemistry 46(7): 934-938.

19. Tracy, R.P., B.M. Psaty, E. Macy, E.G. Bovill, M. Cushman, E.S. Cornell, et al. 1997. Lifetime smoking exposure affects the association of C-reactive protein with cardiovascular disease risk factors and subclinical disease in healthy elderly subjects. Arteriosclerosis, Thrombosis, and Vascular Biology 17(10): 2167-2176.

20. Melbye, H., D.S. Halvorsen, I. Hartz, A. Medbo, J. Brox, A.E. Eggen, et al. 2007. Bronchial airflow limitation, smoking, body mass index, and statin use are strongly associated with the Creactive protein level in the elderly. The Tromso Study 2001 Respiratory Medicine 101(12): 2541-2549.

21. Khera, A., G.L. Vega, S.R. Das, C. Ayers, D.K. McGuire, S.M. Grundy, et al. 2009. Sex differences in the relationship between Creactive protein and body fat. Journal of Clinical Endocrinology and Metabolism 94(9): 3251-3258.

22. Ridker, P.M., R.J. Glynn, and C.H. Hennekens. 1998. C-reactive protein adds to the predictive value of total and HDL cholesterol in determining risk of first myocardial infarction. Circulation 97(20): 2007-2011.

23. Pradhan, A.D., J.E. Manson, N. Rifai, J.E. Buring, and P.M. Ridker. 2001. C-reactive protein, interleukin 6, and risk of developing type 2 diabetes mellitus. Journal of the American Medical Association 286(3): 327-334.

24. Khera, A., D.K. McGuire, S.A. Murphy, H.G. Stanek, S.R. Das, W. Vongpatanasin, et al. 2005. Race and gender differences in Creactive protein levels. Journal of the American College of Cardiology 46(3): 464-469.

25. Mannino, D.M., E.S. Ford, and S.C. Redd. 2003. Obstructive and restrictive lung disease and markers of inflammation: data from the third national health and nutrition examination. American Journal of Medicine 114(9): 758-762.

26. Jacobsen, B.K., A.E. Eggen, E.B. Mathiesen, T. Wilsgaard, and I. Njolstad. 2011. Cohort profile: The Tromso Study. International Journal of Epidemiology. doi:10.1093/ije/dyr049.

27. 1995. Standardization of Spirometry,1994 Update. American Thoracic Society. American Journal of Respiratory and Critical Care Medicine 152(3):1107-1136.

28. Langhammer, A., R. Johnsen, A. Gulsvik, T.L. Holmen, and L. Bjermer. 2001. Forced spirometry reference values for Norwegian adults: the Bronchial Obstruction in Nord-Trondelag study. European Respiratory Journal 18(5): 770-779. 